\title{
Seasonality of Gonorrhea in the United States
}

\author{
ChALMERS E. CORNELIUS III, M.D.
}

$\mathbf{T}$ HE GONOCOCCUS is the cause of America's most prevalent reportable bacterial infection. Reported cases increased during and shortly following World War II, reached a peak of 400,639 cases in 1947, and fell to a low of 216,476 cases in 1957 . Since 1957 there has been a steady rise in the number of cases, with a total of 494,227 reported for the United States in the fiscal year ending June 30, 1969 (1). The estimate of the actual number of cases occurring is about 1.5 million (2). Because of the extremely high and increasing incidence of gonorrhea, I felt it would be auspicious to report the seasonal nature of reported cases in the United States.

\section{Source of Data}

Each State and each city of more than 200,000 population sub-

Dr. Cornelius is with the department of dermatology, School of Medicine, University of Pennsylvania, Philadelphia. He was assistant to the chief, Venereal Disease Branch, State and Community Services Division, Center for Disease Control, Health Services and Mental Health Administration, Atlanta, Ga. Tearsheet requests to Chalmers $E$. Cornelius III, M.D., Department of Dermatology, School of Medicine, University of Pennsylvania, Philadelphia, Pa. 19104. mits a quarterly summary of reported cases of gonorrhea to the Venereal Disease Branch of the Center for Disease Control at Atlanta, Ga. Cases for each State and city are subdivided by reporting agency-physicians in private practice or privately operated medical facilities and governmentoperated medical facilities. These data have been published quarterly for a number of years in the VD Statistical Letter.

\section{Methods and Results}

Reported cases of gonorrhea by quarter were taken from consecutive issues of the VD Statistical Letter for the years 1950 through the second half of 1969. A fivequarter moving average was constructed in which each of the middle three quarters was given a weight of two. The moving average is represented by the smooth curve in figure 1 , and the actual number of cases reported each calendar quarter is represented by the irregular curve.

Figure 1 shows that cases reported during the July-September quarter of each year always exceed the annual quarterly mean of cases as represented by the moving average. A decrease in cases always occurs in the January-March quarter of each year.

Seasonal indices for gonorrhea morbidity were calculated by the methods described in standard texts on statistics (3). Because evi- dence that the seasonal pattern was slightly different for the third and fourth quarters during the period of declining morbidity (1950 through 1957) as compared with the period of increasing morbidity (1958 through 1969), calculation of the seasonal indices was limited to data for the period 1958 through 1969.

For each quarter, the ratio of cases actually reported to the moving average was calculated and multiplied by 100 . These ratios are shown by season in figure 2 . The clustering of the ratios for each quarter and the variation of the clusters of ratios from season to season support the validity of the ratios as measures of seasonality. No adjustments were made for the varying number of days among quarters (90 in the first, 91 in the second, and 92 in the third and fourth) because such adjustments would have been minor in relation to the magnitude of the measured seasonality.

The averages of the cases to moving average ratios for each quarter for reported cases of gonorrhea during the period 1958 through 1968 are shown in figure 2 by the connected lines. The actual values of the averages of the ratios are as follows:

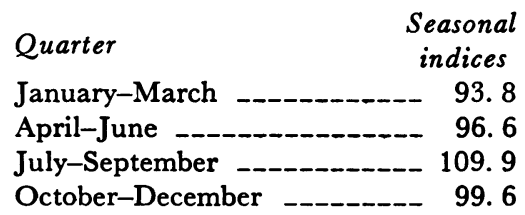




\section{Discussion}

The seasonality of reported cases of gonorrhea implies either one or a combination of the following factors: (a) susceptibility to gonorrhea is seasonal; $(b)$ gonoccus virulence is seasonal; $(c)$ intercourse, particularly frequency of promiscuous intercourse, is seasonal; $(d)$ frequency of reporting to medical facilities by patients varies seasonally; or $(e)$ reporting of data is seasonal.

We have not devised any statistical or laboratory means of testing hypotheses $a$ and $b$ at the present. Since gonorrhea is nearly always contracted by sexual intercourse, usually of a promiscuous nature, the seasonality of conceptions of legitimate and illegitimate live-born infants might provide evidence as to whether intercourse
Table 1. Seasonal indices of gonorrhea and conception of legitimate and illegitimate live-born infants, by quarter, in 35 States, 1955

\begin{tabular}{|c|c|c|c|}
\hline \multirow{2}{*}{ Quarter } & \multicolumn{2}{|c|}{ Seasonal indices of conception } & \multirow{2}{*}{$\begin{array}{l}\text { Gonorrheal } \\
\text { seasonal } \\
\text { indices }\end{array}$} \\
\hline & Legitimate & Illegitimate & \\
\hline $\begin{array}{l}\text { January-March } \ldots \ldots \ldots \ldots \ldots \\
\text { April-June . . . . . } \ldots \ldots \ldots \ldots \ldots \\
\text { July-September. . } \ldots \ldots \ldots \ldots \ldots \\
\text { October-December. . } \ldots \ldots \ldots \ldots\end{array}$ & $\begin{array}{r}105.0 \\
98.7 \\
93.7 \\
102.6\end{array}$ & $\begin{array}{r}100.8 \\
102.7 \\
94.8 \\
101.7\end{array}$ & $\begin{array}{r}94.3 \\
97.0 \\
110.4 \\
98.4\end{array}$ \\
\hline
\end{tabular}

Table 2. Seasonal indices of gonorrhea cases by sex and quarter, 1962-66

\begin{tabular}{|c|c|c|c|c|}
\hline \multirow{2}{*}{ Sex } & \multicolumn{4}{|c|}{ Calendar quarter } \\
\hline & First & Second & Third & Fourth \\
\hline $\begin{array}{l}\text { Male } \ldots \ldots \ldots \ldots \\
\text { Female . . . . . . . . }\end{array}$ & $\begin{array}{l}94.1 \\
94.9\end{array}$ & $\begin{array}{l}96.5 \\
96.8\end{array}$ & $\begin{array}{l}111.4 \\
106.5\end{array}$ & $\begin{array}{r}98.0 \\
100.9\end{array}$ \\
\hline U.S. total. & 94.3 & 96.6 & 110.2 & 98.7 \\
\hline
\end{tabular}

Figure 1. Reported cases of gonorrhea by quarter and five-quarter moving average, United States, 1950-69

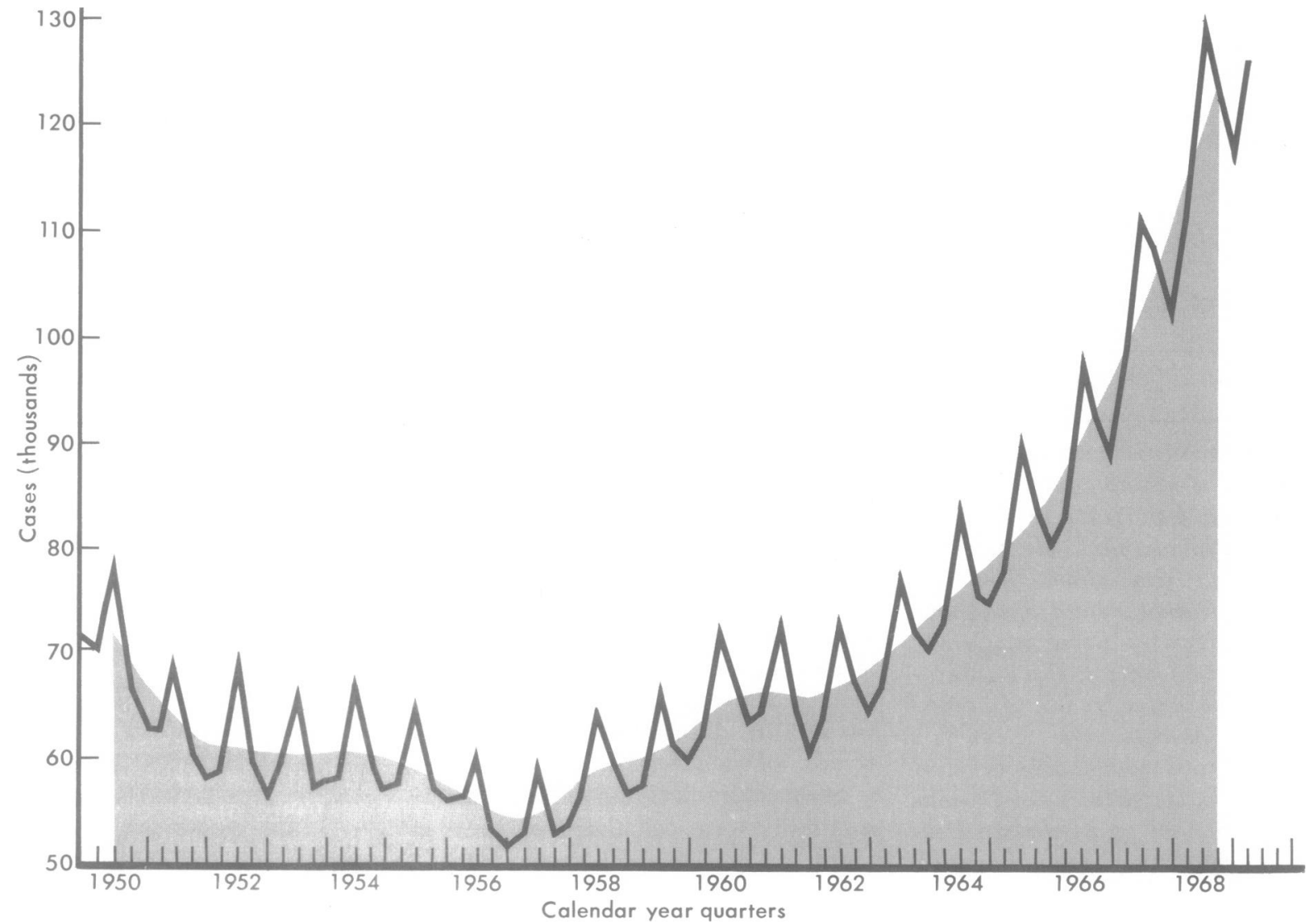


Figure 2. Ratios (X 100) of reported cases of gonorrhea to the fivequarter moving average, United States, 1958-68

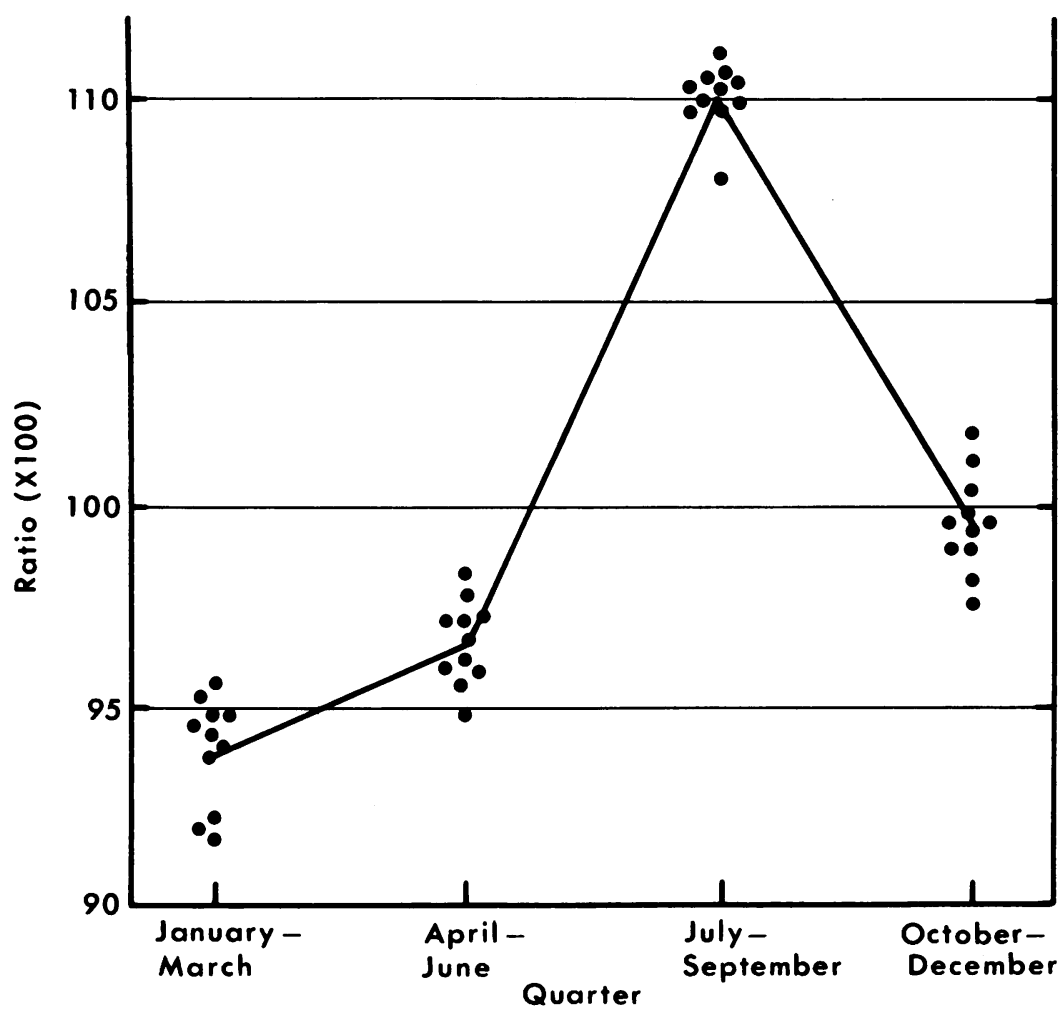

be reduced if the female or male, or both, were already infected at the time of intercourse.

A breakdown of cases nationwide by sex and quarter has not been available since 1966 . To explore seasonality differences or similarities by sex, however, the seasonal indices shown in table 2 were computed for 1962 through 1966. Similar seasonal patterns were observed for both sexes.

Several States and cities with severe winters and several States and cities with mild winters were preselected, their morbidity pooled, and seasonal indices for the years 1965 through 1969 were calculated for contrast. Considerable variation in the seasonal pattern from year to year existed in some of these individual areas. However, when morbidity is small (less than 1,000 cases a quarter) chance variation because of small numbers could easily equal or exceed the seasonal variation which is being measured. Also, the indices calculated for the pool to a large degree reflect the seasonality is a factor. Seasonal indices of legitimate and illegitimate conceptions, computed from monthly birth figures of 35 reporting States in 1955 (4), are compared with gonorrheal seasonal indices in table 1.

The seasonality of both legitimate and illegitimate conceptions appeared generally to be the reverse of the seasonality of gonorrhea. In the July-September quarter, when gonorrhea was at its peak, conceptions resulting in live births were at their lowest. In each of the other quarters, the incidence of gonorrhea was below the quarterly average but, with the exception of illegitimate conceptions for the July-September quarter, conceptions were above the norm. The meaning of these opposite patterns of seasonality is not clear. It is possible that conception could
Table 3. Seasonal indices of gonorrhea in selected areas, by quarter, 1965-69

\begin{tabular}{|c|c|c|c|c|}
\hline \multirow{2}{*}{ Climate, selected States, and cities } & \multicolumn{4}{|c|}{ Calendar quarter } \\
\hline & First & Second & Third & Fourth \\
\hline $\begin{array}{l}\text { weather areas: Alaska, Minnesota, } \\
\text { isconsin, and all New England States... }\end{array}$ & 93.7 & 93.8 & 108. 6 & 104.5 \\
\hline d Florida............................ & 98.6 & 100.8 & 104. 6 & 91.5 \\
\hline 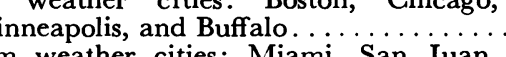 & 93.9 & 93.7 & 112. 2 & 100.8 \\
\hline $\begin{array}{l}\text { m weatner cities: Mrami, san J } \\
\text { n Diego, and Honolulu.......... }\end{array}$ & 95.7 & 100. 2 & 105. 7 & 95.5 \\
\hline
\end{tabular}

Table 4. Seasonal indices of gonorrhea cases by source of morbidity report, by quarter, 1965-69

\begin{tabular}{|c|c|c|c|c|}
\hline \multirow{2}{*}{ Source of report } & \multicolumn{4}{|c|}{ Calendar quarter } \\
\hline & First & Second & Third & Fourth \\
\hline Private practice. . . & 93. 9 & 95. 1 & 106. 7 & 104. 1 \\
\hline Public facilities. . & 92. 2 & 97.3 & 110.1 & 99.9 \\
\hline$\ldots \ldots \ldots$ & 92.7 & 96.7 & 109. 1 & 101.1 \\
\hline
\end{tabular}


of the large morbidity contributors to the pool.

Seasonal patterns for States and cities with contrasting winter climates are shown in table 3 . Considerable variations existed among the contrasting pairs of areas but, for each classification, the peak season for gonorrhea infections was the July-September quarter.

Although there was no reason to believe that the seasonal pattern of cases diagnosed and reported by public facilities would differ from those reported by physicians in private practice, seasonal indices for these two categories of cases were computed based on data from 1965 to 1969 (table 4). For precise comparability of time pe- riods, indices for the total United States were recalculated based only on experience for the period 1965 through 1969.

An excess of cases appears in the third quarter for both categories of cases, but the magnitude of seasonality appears to be somewhat less for persons privately treated than for those treated in government-sponsored facilities. This tendency could be attributed to the fact that the majority of physicians take vacations during the third quarter.

Seasonal indices based on 1965 through 1969 data were similarly computed for all cities in the United States having more than 200,000 population for contrast

Table 5. Seasonal indices of gonorrhea in major cities and the rest of the nation, by quarter, 1965-69

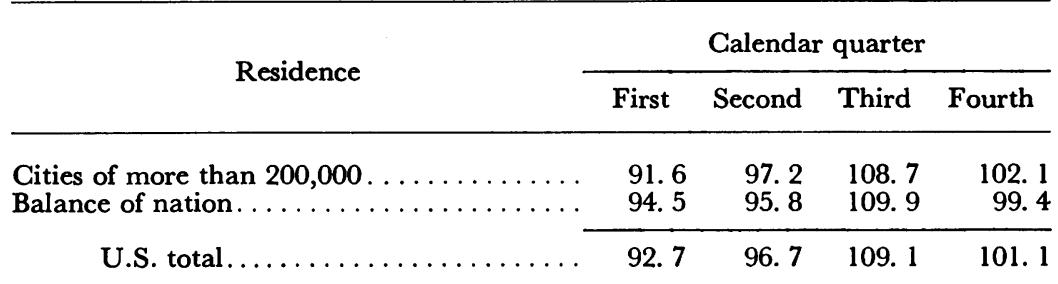

with cases reported among the residents of the remainder of the country (table 5). Similar seasonal patterns were also noted in these two categories of cases. An obvious application of this information about the seasonality of gonorrhea is that control methods should be increased during the third quarter.

\section{REFERENCES}

(1) National Communicable Disease Center: Cases of venereal disease reported to the Public Health Service by State and territorial health departments for each quarter. VD Statistical Letter, No. 103, November 1969, p. 7.

(2) American Social Health Association: Majority of VD cases are not reported. Social Health News 44:1-4, January 1969.

(3) Croxton, F. E., and Cowden, D. J.: Applied general statistics. Prentice-Hall, Inc., New York, 1944, pp. 464-498.

(4) U.S. National Office of Vital Statistics: Illegitimate births: United States, 1938-57. Vital Statistics Division, vol. 47, No. 8, U.S. Government Printing Office, Washington, D.C., Sept. $30,1960$.

CORNELIUS, CHALMERS E., III (University of Pennsylvania): Seasonality of gonorrhea in the United States. HSMHA Health Reports, Vol. 86, February 1971, pp. 157-160.

Reported cases of gonorrhea by quarter from both public and private sources were taken from consecutive issues of the VD Statistical Letter for the years 1950 through the second half of 1969. There was a consistent increase in reported morbidity from the first to the third quarter and a decline in the fourth quarter. This variation expressed a time of seasonal indices as follows:

$\begin{array}{lr}\text { Quarter } & \text { Seasonal indices } \\ \text { January-March } & \begin{array}{r}93.8 \\ \text { April-June - }-1\end{array} \\ \text { July-September --- } & 96.6 \\ \text { October-December } & \end{array}$

This seasonality was true of both sexes and of hot and cold areas of the United States. The sea- sonality of both legitimate and illegitimate conceptions, however, was the reverse of the seasonality of gonorrhea. The factors that caused this gonorrheal seasonality have yet to be determined.

Seasonal variations among patients reporting to medical facilities were possible but unlikely, for there was a seasonality in areas where there were no climatic variations which would hinder patient reporting; for example, Miami.

The last factor, that reporting of data is seasonal, can be excluded by the fact that the same facilities reporting cases of gonorrhea collect data on other diseases. The reports of other diseases did not vary seasonally. 